Article

\title{
An Integrated Spatial Analysis Computer Environment for Urban-Building Energy in Cities
}

\author{
Yu Sun ${ }^{1,2}$, Elisabete A. Silva ${ }^{3}$, Wei Tian ${ }^{4}$, Ruchi Choudhary ${ }^{5}$ and Hong Leng ${ }^{1,2, *}$ \\ 1 School of Architecture, Harbin Institute of Technology, Key Laboratory of Cold Region Urban and Rural \\ Human Settlement Environment Science and Technology, Ministry of Industry and Information Technology, \\ Harbin 150000, China; 10B934005@hit.edu.cn \\ 2 School of Architecture, Harbin Institute of Technology, Harbin 150006, China \\ 3 Department of Land Economy, Cambridge University, 19 Silver Street, Cambridge CB3 9EP, UK; \\ es424@cam.ac.uk \\ 4 Mechanical Engineering, Tianjin University of Science and Technology, Tianjin 300222, China; tjtianjin@gmail.com \\ 5 Department of Engineering, Cambridge University, Trumpington Street, Cambridge CB2 1PZ, UK; \\ rc488@cam.ac.uk \\ * Correspondence: hitlaura@hit.edu.cn
}

Received: 22 September 2018; Accepted: 6 November 2018; Published: 16 November 2018

\begin{abstract}
In this paper, we developed a new integrated analysis environment in order to thoroughly analyses urban-building energy patterns, named IUBEA (integrated urban building energy analysis), which focuses on energy modeling and analysis of a city's building stock to support district or city-scale efficiency programs. It is argued that cities and towns account for more than two-thirds of world energy consumption. Thus, this paper explores techniques to integrate a spatial analysis environment in the field of urban building energy assessment in cites to make full use of current spatial data relevant to urban-building energy consumption and energy efficiency policies. We illustrate how multi-scale sampling and analysis for energy consumption and simulate the energy-saving scenarios by taking as an example of Greater London. In the final part, is an application of an agent-based model (ABM) in IUBEA regarding behavioral and economic characteristics of building stocks in the context of building energy efficiency. This paper first describes the basic concept for this integrated spatial analysis environment IUBEA. Then, this paper discusses the main functions for this new environment in detail. The research serves a new paradigm of the multi-scale integrated analysis that can lead to an efficient energy model, which contributes the body of knowledge of energy modeling beyond the single building scale. Findings also proved that $\mathrm{ABM}$ is a feasible tool to tackle intellectual challenges in energy modeling. The final adoption example of Greater London demonstrated that the integrated analysis environment as a feasible tool for building energy consumption have unique advantages and wide applicability.
\end{abstract}

Keywords: integrated spatial analysis; building energy efficiency; multi-resolution analysis; scenario analysis

\section{Introduction}

Cities and towns account for more than two-thirds of world energy consumption [1], a significant proportion of which is spent on operating buildings. Ambitious national energy and emission reduction targets necessitate that energy demand due to buildings is considered as an important measure when any future evolution of a district or city is planned. Not only the accounting of present-day energy consumption of the built environment by regions and by sectors, but also the prediction of achievable reductions to meet relevant 2020-2050 emissions targets. Indeed, in order to reduce energy consumption and associated carbon emissions globally, more attention should be focused on 
urban-scale energy analysis of the built environment. Urban planners typically use spatial analysis techniques to inform planning decisions. Ascione et al. developed a domestic energy demand model for both winter and summer and with reference to the entire urban context, and the methodology is transferred into Geographic Information Systems (GISs) [2]. A number of studies have been performed to analyse the possibility of using geospatial parameters to reflect the relative influence on energy demand, such as local temperatures, floor space index, and composition of building types [3-11]. However, there is a lack of an integrated spatial analysis platform that can allow for urban planners to run standard urban planning analysis that can make full use of current spatial data relevant to energy consumed by the built environment.

More importantly, many studies have proven that human behavior has a significant role in energy consumption patterns of buildings in urban settings. The uncertainty that is caused by occupant behaviors accounts for a significant discrepancy between the predicted and actual energy usage [12-15]. Yusuke Kishita et al. point out one critical obstacle in planning long-term strategies for achieving an energy efficiency society is the uncertainty of various external factors, such as consumers' behaviors and technological advancement [16]. Timm S.N. and Deal B.M. simulated energy use of community college in Illinois by examining how the role of real-time information affects building occupant attitudes and behaviors [17]. Hui Ben and Koen Steemers identified household archetypes and behavioural patterns in order to allow a targeted approach in energy-saving policy and retrofit improvement [18]. Zhao et al. describes a preliminary ABM energy model on simulating commercial buildings modeled as consumer agents that interact with the power grid [19].

In a city, human behaviors may be correlated with variable economic or social reasons, employment, may be correlated with financial status population, household tenure, council tax bands, etc. In these studies, energy consumption (i.e., buildings) is usually modeled as an aggregated, and fixed-load profile on the basis of building consumers in terms of design and operation. These models focused on the electricity generation and transmission in single building level, but cannot model the diversity and dynamics of energy consumption of buildings in terms of behavior and spatial features. However, it is very likely behavior factors affecting energy use have positive spatial autocorrelation in city context. Neighborhoods tend to cluster together with similar energy use behaviors [20-22]. Therefore, it is important to consider spatial effects as well as occupants behaviours in analysing energy consumption patterns of buildings in urban settings.

Therefore, we develop a new integrated analysis platform that can be used to analyses energy consumption patterns due to buildings at the district and city scale, which also enables a technological innovation by agent-based model (ABM) for behavior modeling and scaling-up to the city level. The ABM allows for trade-offs between their environment, societal, and economic impacts to inform planning regulations and policy scenarios.

This new computational model can be used for spatial data visualization, data query, correlation analysis, regression analysis, scenario analysis, and optimization of districts. The model is named integrated urban building energy analysis (IUBEA) from the initial letters of Integrated Urban Building Energy Analysis. The data used in the IUBEA includes physical features of buildings (e.g., size, volume) per use type and per district, demographics, economics (e.g., cost of land), and energy data at various spatial scales in cities. Another important feature of this computer model is that it is programmed within an open-source software (Netlogo), which allows other users to access it easily. In addition to being open-source, Netlogo [23] is chosen in this project because it has many functions, such as scenario-based analysis, GIS (geographic information system) environment, and agent-based modelling. Furthermore, it has several extensions to link with other programs, such as statistical program $\mathrm{R}$ and numerical computing environment MATLAB.

In IUBEA, we implemented the ABM model through a case study of London. Agent-based modeling $(\mathrm{ABM})$ is a technique for bottom-up modeling, providing an alternative perspective to those that can be attained by using optimization or general-equilibrium approaches [19]. Findings proved that $\mathrm{ABM}$ is a serves a new paradigm of integrated analysis with transparency and user interactivity. 
This paper explores techniques to integrate a spatial analysis environment in the field of urban building energy assessment in cites to make full use of current spatial data relevant to urban-building energy consumption and energy efficiency policies. So, users of the model is able to easily relate building and spatial characteristics parameters to policy or utility figures, which can lead to an efficient energy model, which contributes the body of knowledge of energy modeling beyond the single building scale.

\section{Materials and Methods}

\subsection{Conceptual Framework}

The objective of this research is to develop a computer model for integrated spatial analysis of energy use in cities. This computer model, called IUEBA, considers many issues being raised in energy planning of cities:

(1) Spatial visualization: One of the most important features in urban-energy analysis of the built environment is to display the data at various spatial scales. Hence, this environment should have basic spatial functions, such as visualization, data querying, etc.

(2) Statistical Analysis: This environment should also have some statistical analysis functions, like: statistical regression and scenario analysis. Statistical regression analysis can be used to analyses the relationship between energy use of districts and other physical/social/economic variables. The scenario analysis is more focused on what-if analysis, which is often of interest to urban planners. For instance, a planner may be interested in how future evolution of building types may affect energy use in some part of cities.

(3) Function extension: The environment should be open source, hence available to other analysts who want to develop their new functions.

(4) Easy operation: The environment should be easy to operate for new researchers in this area.

(5) Public domain software: The environment should be available for most of building energy analysts and urban planners. Considering the requirements above, NetLogo has been chosen in this project. Figure 1 shows the technical route of IUBEA, including the data layer, the algorithms, and software layer. By using Netlogo, both spatial visualization and statistical data analysis can be implemented to understand the patterns of energy consumption due to buildings in an urban environment.

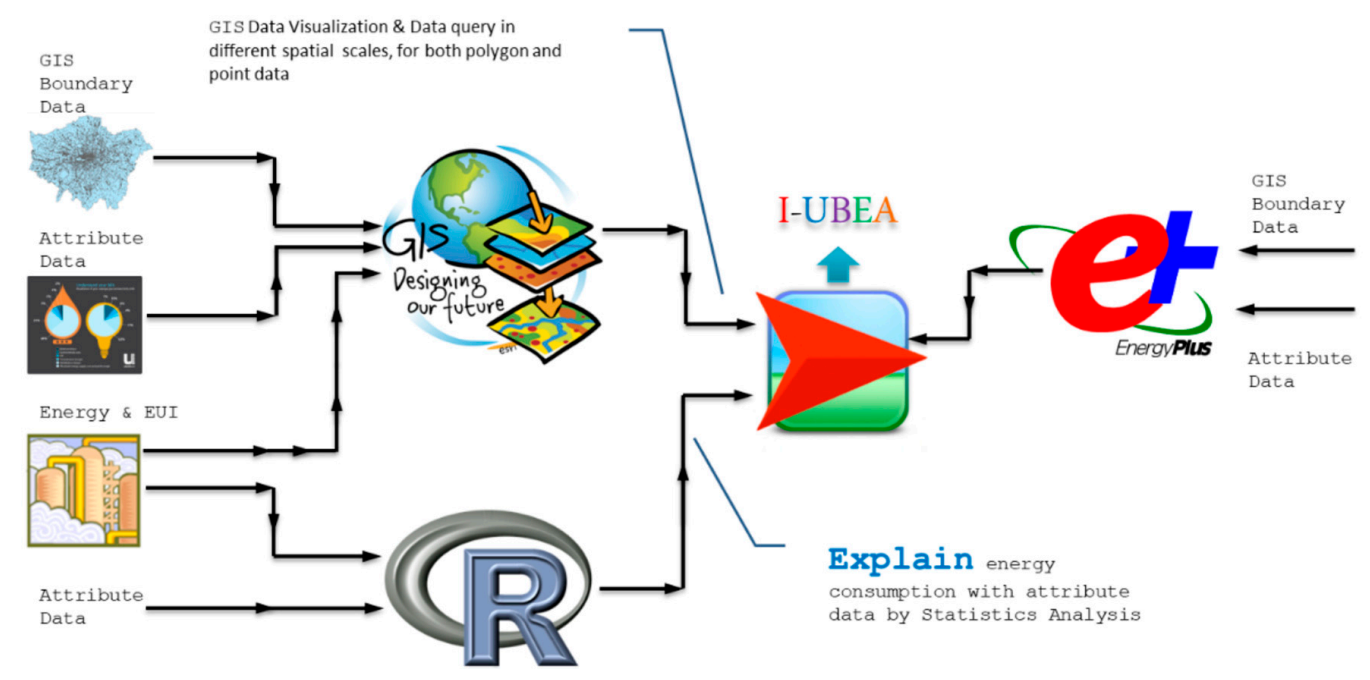

Figure 1. The technical route of integrated urban building energy analysis (IUBEA).

\subsection{Data integration for Multi-Resolution Analysis}

As displayed in Figure 1, the data required includes spatial boundary GIS data, energy data, and attribute data. Geographically, boundary data of cities is used to display the data at different spatial 
scales. Energy data and corresponding attribute data are necessary for energy analysis. The energy and the corresponding attribute data (and both of them) can be either polygon type or point data, but with the same resolution as the GIS boundary data. Attribute data here denotes the factors influencing energy consumption of districts, such as floor area of buildings, building use, population, number of households and employment, household incomes, etc. The polygon data here means the regional data in a given spatial boundary, while the point data is usually for individual buildings.

\subsection{Description of the Main Features of IUEBA}

Figure 2 shows the interface of IUEBA in scenario analysis. As an example, it displays non-domestic electricity consumption per household in London at the middle super output area (MSOA) level (which can be indicative of the level of commercial activity within a district). The interface is organized in four parts: global operations (in the left), local operations (in the right), main window (in the middle), and information outputs (below the main window). Global operations are to setup the system, add or delete variables, calculate, and display the results. These operations are necessary for most of functions in IUEBA. Local operations are designed to select relevant variables and the corresponding analysis in the project. These operations are deemed 'local' because users only need to select the analysis or variables that they are interested in. The main window displays the city map, GIS data, and calculation results. The information outputs, including both numeric outputs and plots, provide more detailed information of operations and outputs depending on different types of analysis.

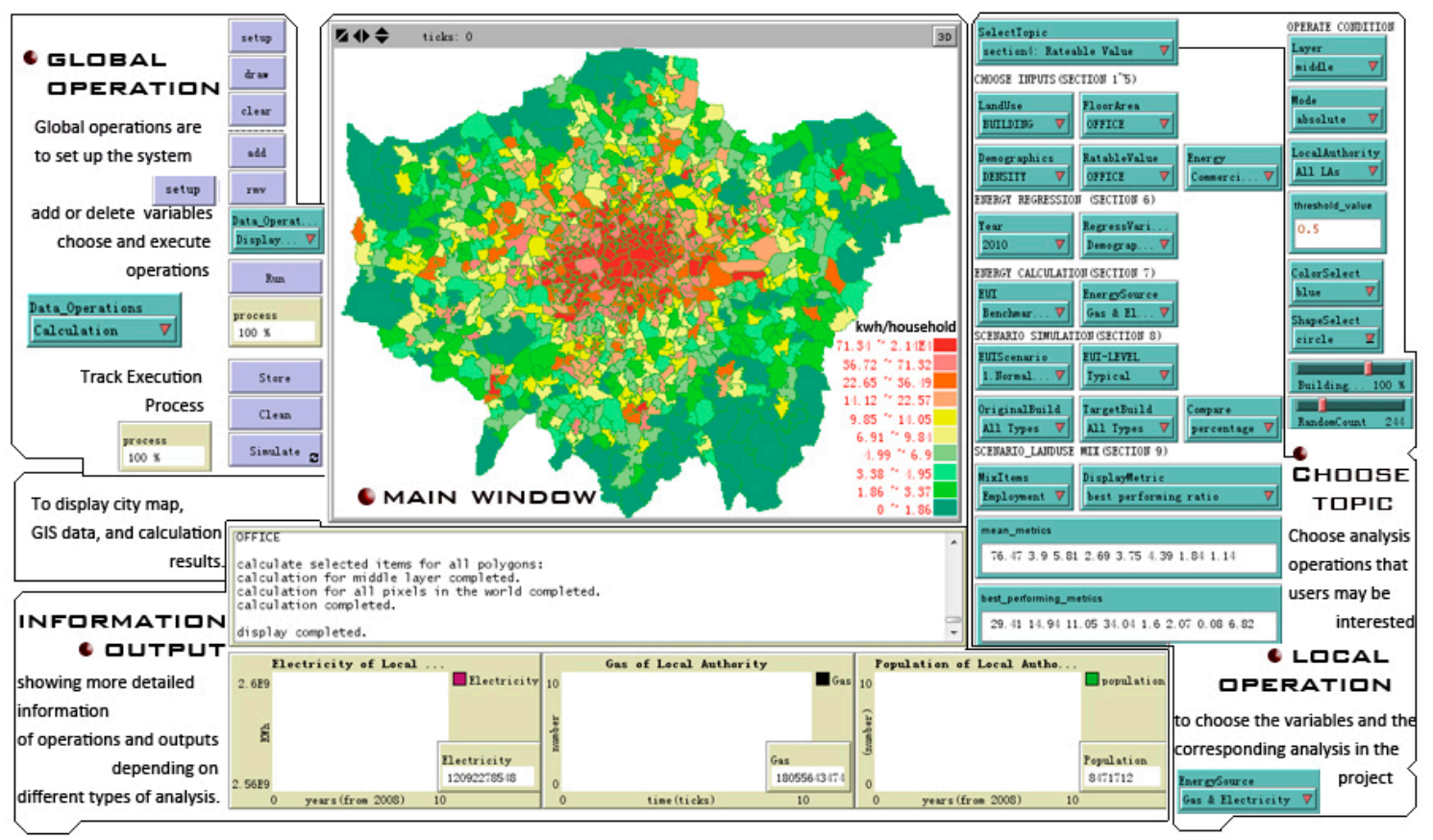

Figure 2. The interface of an integrated energy analysis environment IUBEA (integrated urban building energy analysis) interface shows distribution of commercial electricity per household in London at middle super output area (MSOA) level.

\section{Main Functions}

The analyses in IUEBA are implemented through four functions. The first displays the data spatially and can be used for data query at different spatial levels in cities. The second is to explore the relationship between various factors and energy consumption using correlation and regression analysis and create statistical energy models. The third is to study the effects of different scenarios on building energy use, named "scenario analysis". The fourth is to investigate the optimization zones using mixed-use method based on energy use intensity of districts. This section will describe these four main functions in detail. 


\subsection{Spatial Visualization and Data Query of City Scale Energy in IUEBA}

IUBEA can be used to display both polygon and point data in cities. The user can choose the relevant spatial scale for analysis. For example, a city can be divided into ten districts, or further subdivided into hundreds of smaller neighborhoods, in which there are several data sets, such as energy and population. This city may be also further subdivided into one hundred small areas for more detailed analysis, such as population and employment. The model can be easily switched to any spatial scale during the analysis.

IUEBA supports data query. For instance, analysts may want to know how many areas in a city consume more than the average electricity across districts. This query can be also used to obtain the minimum and maximum values for a given variable. For example, this function can find a zone that has the largest energy consumption in a city.

The environment can also display data in either absolute or relative mode. Absolute mode means to display the values that are associated with an attribute directly. Relative mode displays the data as percentage or ratio of a reference value. For a land use category and for the floor area of a certain building type, the relative mode displays the percentage of selected land use or floor area of a building type in a district, with respect to the total land area and floor area of buildings in the district, respectively. The relative mode for all other data (demographics, ratable value, and energy consumption) is calculated as per (1), which is essentially normalizing the data with respect to its maximal value across all districts.

$$
s_{r i}=\frac{S_{i}}{\sum_{j=1}^{N} S_{j}}
$$

In Equation (1), $S_{i}$ is the value of selected floor area data in current polygon $i, N$ is the number of building types in polygon $i, i$. The relative value of polygon $i$ for energy/cost/demographics, $r_{i}$, is formulated as

$$
r_{i}=\frac{E_{i}-E_{\min }}{E_{\max }-E_{\min }}
$$

In Equation (2), $E_{i}$ is the energy/cost/demographics of polygon $i$, and $E_{\max }$ and $E_{\min }$ are the maximal and minimal value of data in all polygons, respectively; and, $s_{r}$ is calculated as relative result.

The total energy consumption of buildings in a district can be expressed as the sum of energy consumption of its constituent buildings in the following form:

$$
E_{k}=\sum_{i=1}^{N} \operatorname{EUI}(i) \cdot P A(i, k)
$$

where, $E_{k}$ is the energy consumption of a district $k$ in $\mathrm{kWh} / \mathrm{m}^{2} /$ year, normalized by its total building floor area. $E U I(i)$ is the energy use intensity of a building type $i$ in $\mathrm{kWh} / \mathrm{m}^{2} /$ year, $P A(i, k)$ is the percentage of built floor area of building type $i$ in district $k$, and $N$ is the total number of building types.

\subsection{Correlation Analysis of Energy Efficiency}

The analysis in this project has two main aims: interpretation and prediction. Both correlation and regression analysis can be used for interpretation, while only regression can be used for the purpose of prediction. Interpretation is to understand the relationship between energy and various independent variables. For instance, analysts may be interested in how the population number or floor area influences the energy consumption of districts, and which of the two variables has more significant effects on energy consumption. Prediction is used to investigate how changes in independent variables will result in changing the energy consumption of a district. For example, it may be of interest to quantify the change in energy consumption due to future growth of household or population numbers. Note that, whilst regression analysis can deal with one or multiple independent variables, the correlation analysis is used for only two variables. 
The regression analysis currently implemented in IUBEA concerns the influence of land use in different districts of London on their energy consumption in Equation (4). In this example, nine categories of land use and 10 categories buildings of non-domestic buildings in London are considered the percentage share.

$$
\hat{E}_{t}=\text { constant }+\beta_{\text {building }} \times S_{t}^{\text {building }}+\beta_{\text {road }} \times S_{t}^{\text {road }}+\cdots+\varepsilon
$$

where: $\hat{E}_{t}$ is estimated energy consumption of a given area $\mathrm{t} ; \beta_{\text {building }}, \beta_{\text {road }}, \ldots$, are the coefficient of building, road, etc.; $S_{t}^{\text {building }}, S_{t}^{\text {road }}, \ldots$, are the area of building, road, etc. in a given area $t ; \varepsilon$ is the random error term.

The equation above is only suitable for linear models. More complicated non-parametric regression methods will be added in a future version of IUBEA to analyses non-linear relationships.

\subsection{Energy Scenario Analysis}

Scenario analysis is used for what-if analysis. The function in this section is different from "regression analysis", as explained in Section 3.2. Scenario analysis does not implement regression method but it depends on only independent variables. Therefore, this method is more flexible compared to regression analysis because it is suitable for the situation where energy consumption data are unavailable in some spatial scales or some areas of a city. To implement the scenario analysis, analysts should have good knowledge on the effects of these independent variables on energy consumption. Furthermore, some form of validation of energy calculations is necessary to confirm that the prior assumptions in the model are appropriate.

To illustrate this method, an example is given based on floor area per building type because energy use per floor area in terms of building types is more well-known in comparison with other independent variables, such as population, employment, and income. Firstly, this section is to describe the formulation and methodology use in this energy scenario analysis. Then, the baseline scenario is discussed to compare the calculated energy use with actual energy data. The third section is to discuss three different scenarios: electrification, change of building types, and improvement of energy efficiency.

\subsubsection{Baseline Scenario}

The total energy consumption of buildings in a district can be expressed as the sum of energy consumption of its constituent buildings in the form of Equation (3).

This baseline scenario is to compare the calculated energy consumption with the actual energy consumption in cities. This step is very important. Therefore, analysts may use different assumptions based on their prior knowledge on energy use intensity in terms of building types. In this environment, may be based on three different sources of information: benchmark values, median values, and Monte Carlo method. The benchmark values are based on low, typical, and high values (EUI) provided in standards, such as the CIBSE Guide F and CIBSE TM46. The median values are from actual observational energy data, but only use median values for different building types. Display Energy Certificate (DEC) and Energy Performance Certificate (EPC) data. Monte Carlo method is from actual energy data to directly sample the values from these actual data randomly in order to calculate the distributions of total energy use. Analysts may choose one or all these three methods based on data availability. As more building energy use data becomes available, the third method may be used to thoroughly explore building energy consumption patterns in cities.

\subsubsection{New Scenario}

This section will describe three new scenarios to explore the possible change of energy consumption in cities. 
(1) Electrification scenario: It seems that there are more benefits for electrification in building sector if grid electricity can become gradually less carbon intensive. As an example, electricity emission factors in the UK have been reduced around 35\% from 1990 to 2010 [24]. This energy scenario is to explore how the total energy or carbon emissions would change if the building sector would use electricity instead of gas for heating.

(2) Building type conversion scenario: In urban environment, it may have to change building types due to economic or social reasons. Then, it may be of interest to investigate the change of building types on the energy consumption in cities.

(3) Energy efficient Scenario: In order to reduce carbon emissions, it is important to understand how the improvement of energy use efficiency may influence the energy consumption in cities. Thus, this scenario allows analysts studying the influences of change of energy use intensities for different building types.

\subsection{Energy Optimization Based on Compositional Data}

The purpose of energy optimization in this section is to find the best energy performance area in a city and calculate the overall difference of compositional data (independent variables) from this best area and other areas. The overall differences mean the extent of efforts that are needed for a specific area to get the best area ratios in best performance area in terms of energy consumption. The compositional data here means the elements are not negative and sum to unity. For instance, the proportion of floor area for different building types in an area can be regarded as compositional data.

As an example, the following descriptions are based on the proportions of floor area in different building types in different city areas. It is assumed that a city has ten districts and the buildings can be divided into five types: residential, office, retail, education, and others. Both the energy consumption and the proportions of floor area in terms of five building types in these ten areas are available. The calculation for energy optimization is as follows:

(1) obtain energy consumption intensity normalized by total floor area in all ten districts; and,

(2) find the area with the minimum energy intensity from all the ten districts. This area (called BEST area) is regarded as the best energy performance area.

(3) Use the proportions of five building types in this BEST area as a base case to obtain the absolute differences of proportions for all the other nine areas. Then average these differences to obtain the overall differences for all these nine areas. Apparently, the overall difference for the BEST area is zero.

(4) Rank all the areas based on these overall differences in all the area.

The calculation that is described above is a simple method to find the best energy performance zone and also can assess the differences of compositional data from this best performance area and other areas. The independent variables may include floor area for different building types, household number for different house types, land area for different land uses, employment for different industries, population numbers for different age groups, etc. The best performance areas in terms of these single indicators may be different. If it is assumed that these indicators are equally important, analysts can find the best energy performance zone with the least rank numbers by averaging all of these ranks from different indicators.

\subsection{Agent-Based Energy Model}

\subsubsection{Implement Agent-Based Model (ABM) for Energy Efficiency and Behaviour Simulation}

The application of this section will facilitate the deployment of energy efficient buildings, socio-economic impacts and energy supply technologies in city design, by developing quantifiable, system-level models that assess their feasibility and implementation in the wider context of socio-economic, and regulatory characteristics of the city. The system-level model will not only enable a more robust scaling-up of the impact of technological innovations up to the city level, but also allow for trade-offs between their environment, societal, and economic impacts to inform regulations and policy scenarios. 


\subsubsection{Formulation and Methodology of Model Simulation}

This work seeks to provide an integrated, spatially and temporally diverse representation of urban energy use but within a generalized framework. The 'integrated' and 'diversity' mean integration of multiple supply vectors and diverse resource demand, respectively. As the heart, human-activity simulation with agent based model and micro-simulation generate all resource demand in various sites, like retail, cinema, school, office, factory, etc. Resource demand are clustered and converted into various energy consumptions, such as domestic electricity, commercial gas, etc. Human short-term and long-term interventions are critical for an Urban Energy Model. In this research, they are supported and implemented through a flexible way, policy-agents.

The major assumption of this approach is that the optimal distribution of resources in spatial polygons could improve energy use intensity. Each polygon has character named "spatial characteristics", which is determined by its social structure and economy level. Social structure consists of population density, land density (domestic floor area), employment density, density of industry), and economy level consists of: land cost. Distribution of energy is related to population and employment. We assume that population will migrate to neighboring polygons finding better resources by policies influence. The judgment of better resource is determined by policies. People migrate to neighboring MSOA according to accumulation of different energy sources.

Weights of each energy source can be set for denoting different policies. Depending on the use case, the object can be filtered to a subset of buildings by building type, year built, total floor area, energy use intensity (EUI), and peak electricity load per area.

1. Initiate model Environment in IUBEA:

- Energy Consumption Source: Lighting, HVAC (heating, ventilation, air-condition, cooling), Equipment.

- $\quad$ Energy Sources: Gas, (Oil), Electricity, Renewable Energy (Solar, Wind, Biogas, Bio-diesel).

- Environment Sources: Residential, Commercial, Industrial, Transport

2. Formulation and Methodology

$$
E U I_{m s o a}=\alpha \times e^{\frac{N_{\text {population }}}{c_{p} \times \sum_{J=1}^{M} s_{\text {building }}}}+\beta \times e^{\frac{N_{\text {employment }}}{c_{e} \times \sum_{J=1}^{M} s_{\text {building }}}}
$$

where $E U I_{m s o a}$ is the energy use intensity of middle super output area (MSOA). $N_{\text {population }}$ and $N_{\text {employment }}$ is the number of population and employment, respectively, in MSOA. $S_{\text {building }}$ is the floor area of each building type and $M$ is the number of building types. $c_{p}$ and $c_{e}$ are coefficients to adjust the strength of population and employment that can be determined before regression in order to control the weights of population and employment.

$$
E U I_{\text {msoa }}=\sum_{i=1}^{N} \sum_{j=1}^{M} S_{\text {building }}\left[\alpha \times e^{\frac{N_{\text {population }}}{c_{p} \times \sum_{J=1}^{M} S_{\text {building }}}}+\beta \times e^{\frac{N_{\text {employment }} \times \sum_{J=1}^{M} s_{\text {building }}}{2}}\right]
$$

Equation (2), elaborates the calculation process of energy consumption of local authority $E_{l a}$ based on the EUI computed from Equation (1). $N$ here is the number of MSOA in local authority and $M$ is the number of building types for a specific MSOA.

\section{A Case Study of London Building Energy Analysis}

\subsection{Description of the Analysis Cases}

London has been used as a case study to explore its building energy patterns with this new integrated GIS environment. In this case study, London has been divided into three spatial scales: LA 
(local authority, also called borough), MSOA (middle layer super output area), and LSOA (lower layer super output area). London has 33 LA areas and the city of London is also regarded as a special LA in this study. According to the UK census 2001, London has 983 MSOAs and 4765 LSOAs. MSOA and LSOA areas are created based on population and household number. Note that there is a change of these MSOA and LSOA areas in 2011 census due to population and household changes from 2001 to 2011. In this analysis, the 2001 version has been used in order to be in line with the energy data that are based on 2001 MSOA and LSOA areas.

Table 1 lists the data sets that were used in this paper. These data can be divided into three categories: energy, area, and social economic factors. The data used in this analysis is from the year of 2010 if not specified.

Table 1. Date source used in this analysis.

\begin{tabular}{ccc}
\hline Theme & Data Set & Reference \\
\hline \multirow{4}{*}{ Energy } & Electricity/Gas at borough level & (DECC, 2013c) \\
& Electricity/gas at MSOA and LSOA & (DECC, 2013b) (DECC, 2013a) \\
& EPC (energy performance certificate) & (UK DCLG, 2013) \\
Area & DEC (Display energy certificate) & (UK DCLG, 2013) \\
& Land use area & (UKMap, 2011) \\
& Floor area & (UKMap, 2011) (Choudhary, 2012) \\
Social economy & Population & \\
& Household & (London datastore, 2013) \\
& Employment & \\
\hline
\end{tabular}

The energy data includes regional data and point energy data in London. The regional energy data means the total energy in a specific area, while the point energy data is the energy data for individual buildings. Both electricity and gas data in domestic buildings in London have good quality from LA to MSOA levels, although the energy data in a few number of MSOA areas is unavailable [25]. For non-domestic energy data, there are full data at LA level from UK DECC [26]. For MSOA gas data in the London non-domestic sector, the data quality is also fine except for a small numbers of MSOA areas, whereas the electricity data at MSOA level is almost impossible to use since most of data are unavailable due to disclosure issues [27]. The point energy data in this paper is from UK DCLG, including DEC (display energy certificate) and EPC (energy performance certificate) [28].

The second type of data is related to land use and floor area. The land use data is directly from UK Map London [29], while the floor area is based on the method described in [30]. UK Map is a detailed mapping database for London, containing rich information on land use, building types, and building heights.

The third type of data is social economic data, including population, household, employment, and rateable value in London [31]. The rateable values are the open market annual rental value of a non-domestic property from UK VOA (valuation office agency).

\subsection{Results}

As described in Section 3, many types of analysis can be implemented. In this section, we only show some results of corresponding four main functions that are described in Section 3.

\subsubsection{Energy Use and Spatial Factors}

This section is to display the spatial distributions of social-economic factors and the relations with energy consumption in non-domestic properties in visually, such as rateable values, employment, population, etc. Rateable values are the open market annual rental value of a non-domestic property in the UK [32], which is based on various factors, such as location, use, age, size, and physical state. The reasons of choosing this variable is that there might be correlation between rateable values and energy consumption in non-domestic building to some extent. Figure 3a shows spatial distribution of 
the commercial electricity and Figure $3 \mathrm{~b}$ presents the distribution map of rateable values for retail in London at MSOA level. Figure 3c,d illustrate the results of employment and population distributions in London at MSOA level. The empty polygons in white colour denote that there is no data available in these areas.

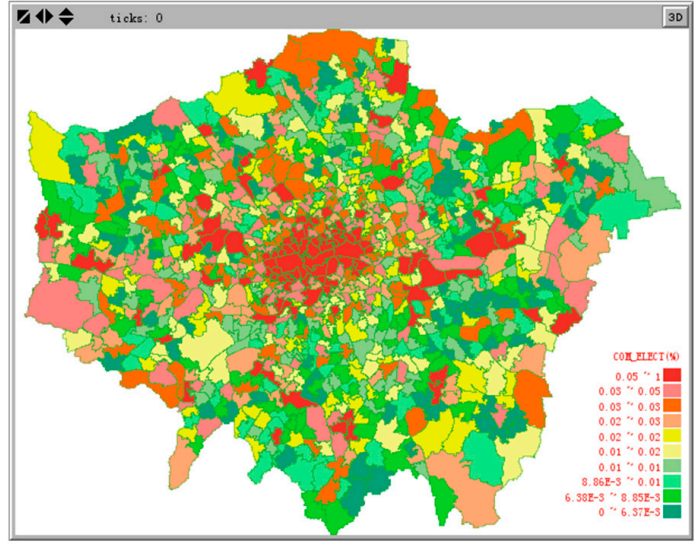

(a) Commercial Electricity (\%)

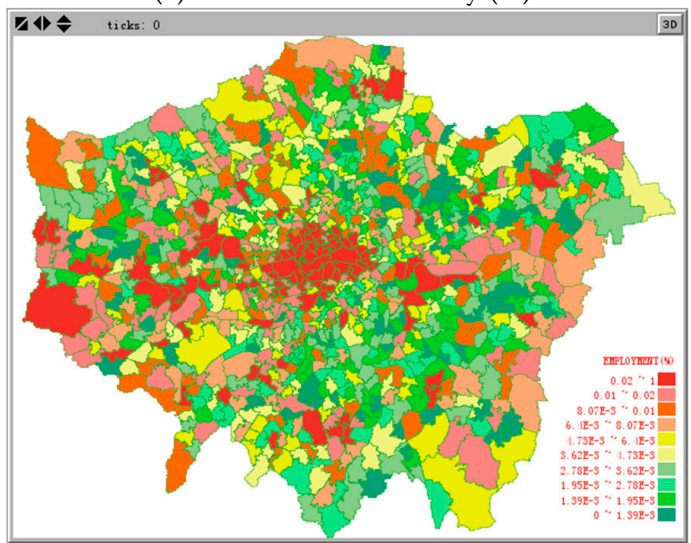

(c) Employment (\%)

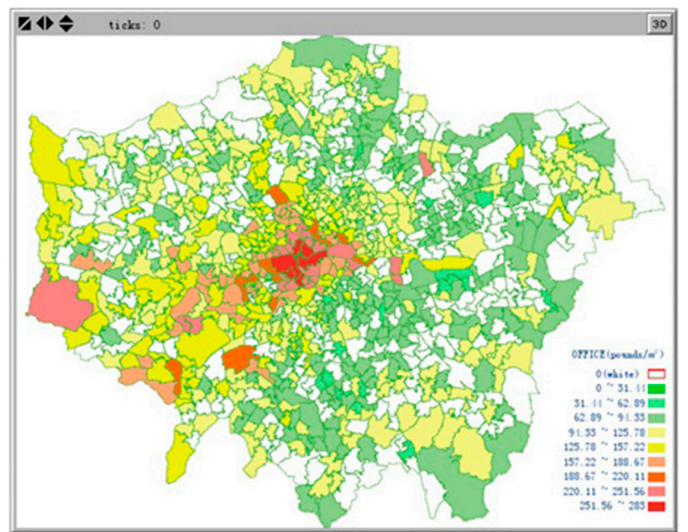

(b) Retail (pound $\left./ \mathrm{m}^{2}\right)$

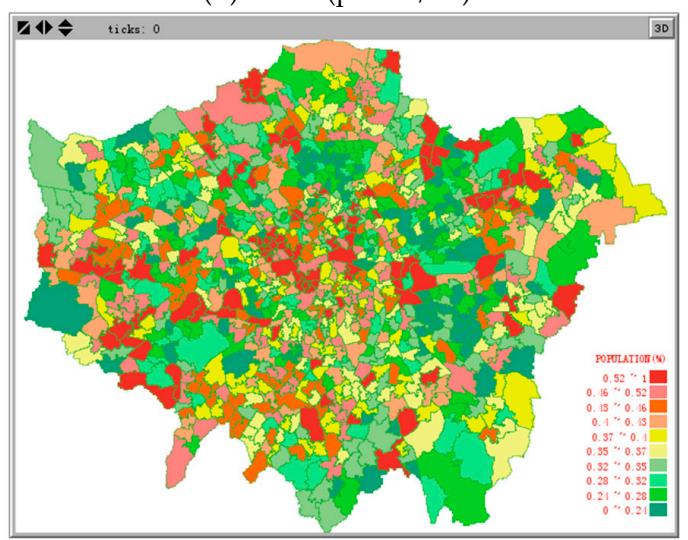

(d) Population (\%)

Figure 3. (a) Commercial Electricity Consumption in London at MSOA level (relative mode); (b) Rateable values of retail and office buildings at London MSOA (absolute mode); (c) Employment distribution in London (relative mode); (d) Population distribution in London (relative mode).

As can be seen from Figure 3, the areas with high rateable values for retail properties are clustered around the centre of London, especially the city of London, Westminster, Kensington \& Chelsea, and Camden. The areas with high rateable values for office properties are also clustered around the centre of London. Besides, Hillingdon borough also has high values for office rateable values possibly due to London Heathrow Airport. By analysing spatial distribution of social-economic and energy date in MSOAS figures show that MSOAs near the city of London consume higher commercial electricity. Employments can explain most of the commercial electricity in MSOA level and the correlation is more obvious near the centre of London.

The correlation analysis has also been implemented to calculate the correlation coefficients between gas/electricity energy intensity $\left(\mathrm{kWh} / \mathrm{m}^{2}\right)$ and total bulk rateable values (pounds $\left./ \mathrm{m}^{2}\right)$ for non-domestic properties at LA levels. MSOA level is not chosen in this analysis, since the electricity data is unavailable at London MSOA level, as explained in Section 4.1. Total bulk rateable values here means the average rateable values for all the properties (including office, retail, warehouse, and industry properties) in a given area. The results indicate that there is a moderate correlation $(0.59)$ between electricity use intensity and all bulk rateable values, while there is a weak correlation (0.11) between gas use intensity and all bulk rateable values. 


\subsubsection{Regression Analysis on Electricity Use with Spatial Factors in City Scale}

This section is to implement regression analysis to explore the relationship between electricity and total floor area, population, or employment at London LA spatial levels. Figure 3 shows the regression results. For the domestic sector, the regression analysis for domestic electricity is applied with the total domestic floor area and the total population number, respectively. For the non-domestic sector, the regression analysis for non-domestic electricity is implemented with the total non-domestic floor area and total employment number, respectively.

For the domestic sector in London, both the domestic floor area and population number have good linear relationships with electricity use in London. The coefficients of determination from two variables are very close, around 0.9 , which means that either floor area or population number can explain approximate $90 \%$ of variations of total electricity use at London LA levels.

For the non-domestic sector in London, the non-domestic floor area can account for around $76 \%$ of the variations of total electricity use, while the employment number can increase this value to $82 \%$. Therefore, when compared to the floor area, the total employment can be more suitable to the electricity consumption at London LA levels.

As also can be seen from Figure 4, the coefficients of determination for domestic sector are less than that from the non-domestic sector in London. This implies that the domestic electricity use is more related to the total floor area in comparison with the non-domestic electricity in London. Another conclusion that can be drawn from this analysis is that the population per floor area in domestic sector is less varied than the employment number per floor area in London. This is because the coefficients of determination from the regression analysis of floor area and employment in London non-domestic buildings would be very close if the employment per floor area is similar at different London LA areas.

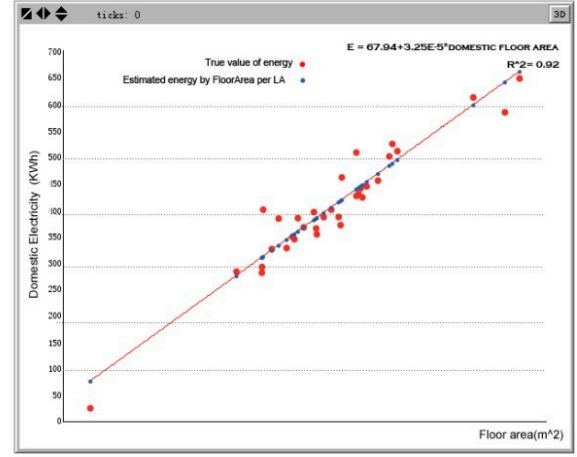

(a)

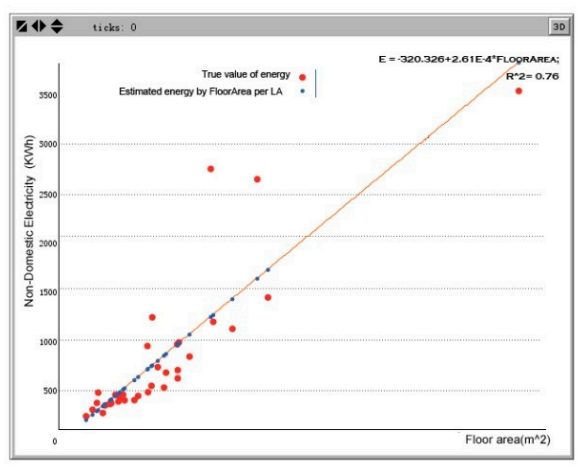

(c)

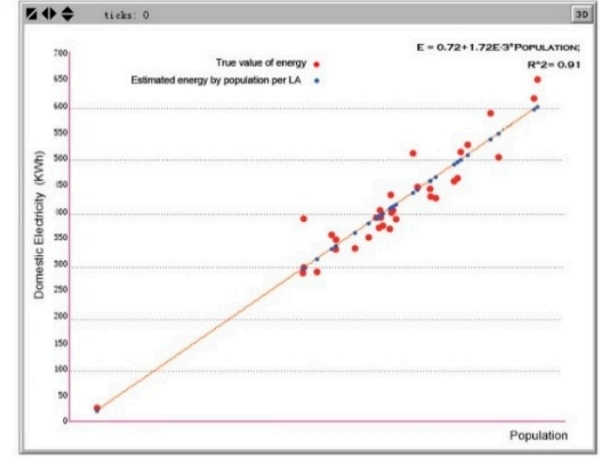

(b)

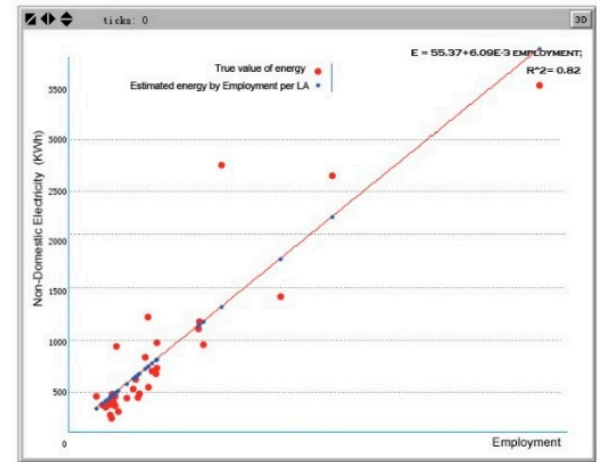

(d)

Figure 4. Regression analysis for spatial-unit electricity and floor area: (a) population with domestic Electricity; (b) employment with domestic Electricity; (c) population with non-domestic electricity; (d) employment with non-domestic Electricity in London LA (local authority) level. 


\subsubsection{Energy Scenarios of Electrification in London Non-Domestic Sector}

This section is to study the effects of full electrification of non-domestic sector at LA level based on the Monte Carlo method, as described in Section 3.3. The distributions of energy use intensity in terms of building types are from UK DEC (display energy certificate) and EPC (energy performance certificate) data [28]. Figure 5a shows a box-plot of the measured area-weighted EUI in 33 LA areas plot of sampling for the average energy usage from DEC and a plot of the average typical value of the benchmark data for each day. Note that the total energy use intensity used in this section is defined as the total energy use divided by the corresponding total floor area in a given LA area.

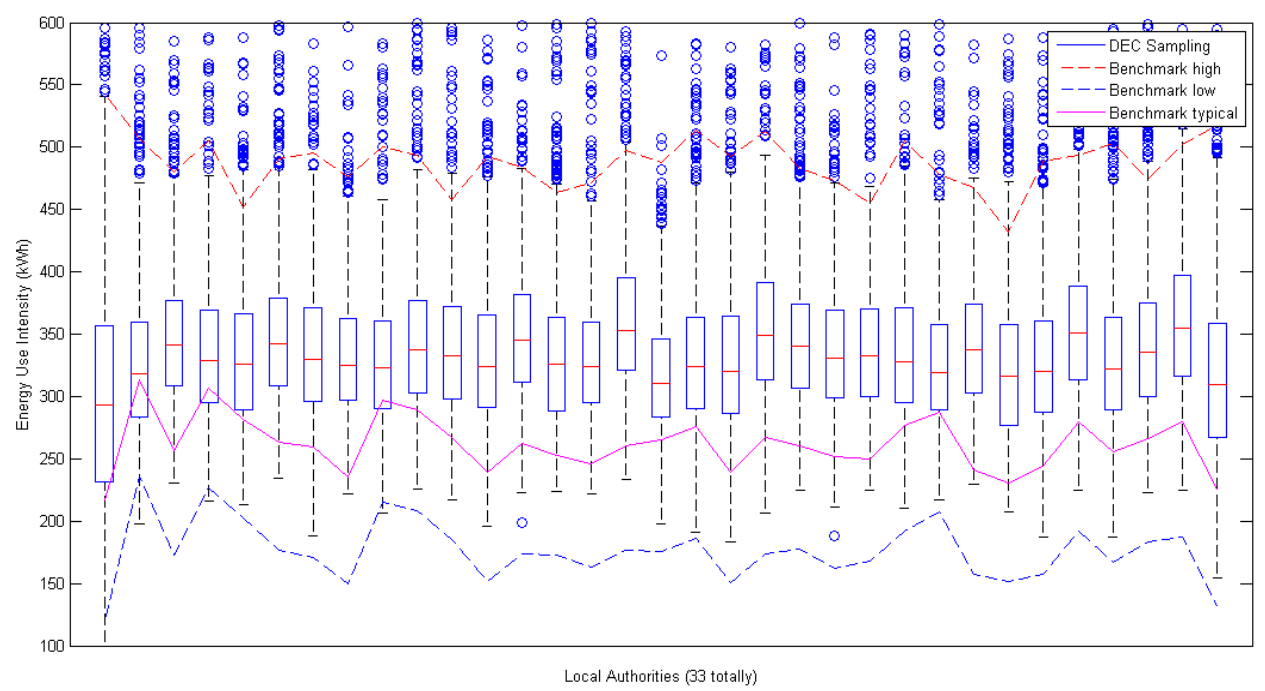

(a) Box-plot of the calculated area-weighted energy use intensity (EUI) in London.

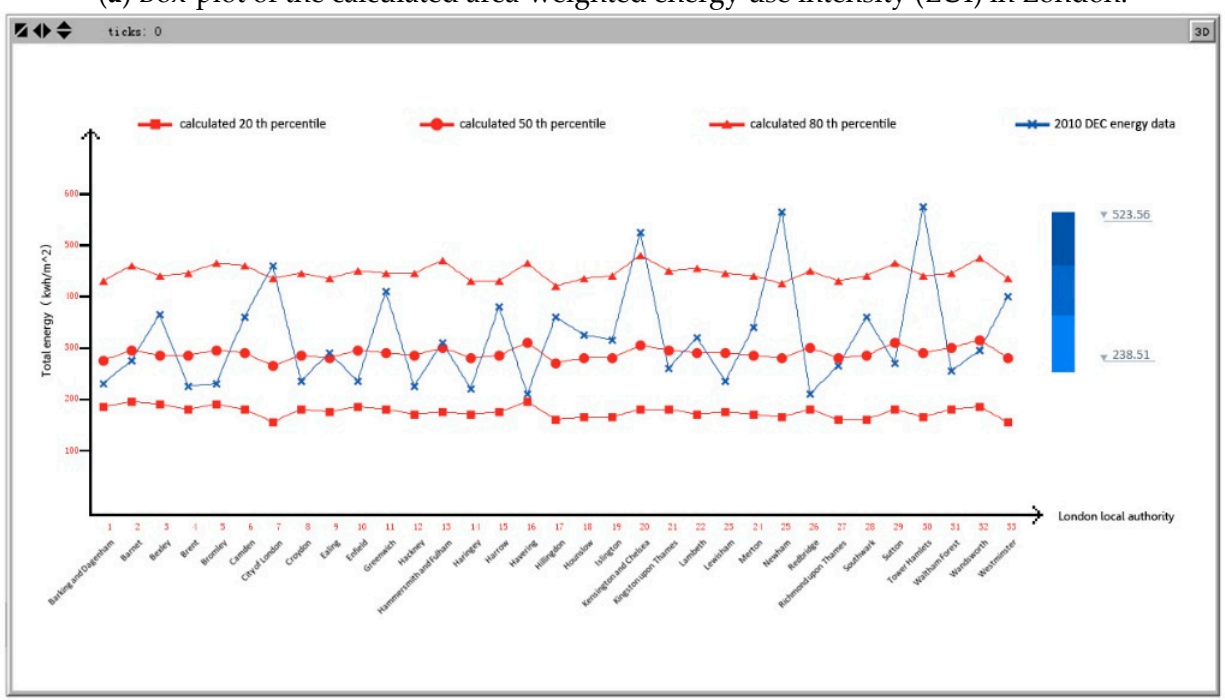

(b) Comparison of calculated (10th, 50th, and 90th percentile) and actual 2010 total energy data

Figure 5. Cont. 


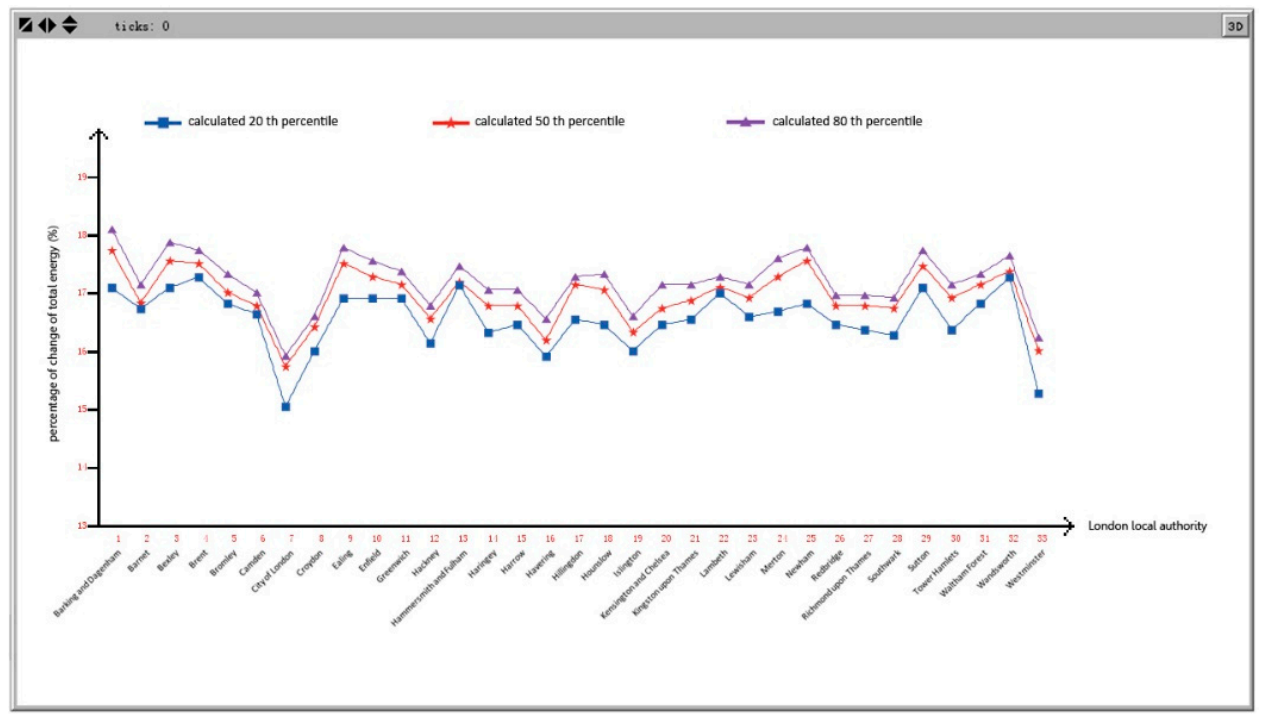

(c) Change (percentage) of energy due to electrification

Figure 5. Results for electrification scenario analysis in London LA (local authority) level.

As discussed in Section 3.3, it is necessary to validate the energy results in baseline scenario. Figure $5 \mathrm{~b}$ shows the comparison of calculated and actual 2010 total energy intensity in 33 LA areas. As can be seen from this figure, most of actual total energy values are within the 80 percent of confidence interval for total calculated energy use. The relative differences between the calculated median and actual 2010 data are below $20 \%$ in around 15 LA areas.

Figure $5 c$ illustrates the relative change of total energy use intensity due to electrification. The conversion efficiency from gas to electricity is taken as 0.7 from [33]. The total energy use intensity would be reduced in most of the London area. The city of London and Westminster have low percentage change in comparison with other LA areas. This is because the gas use accounts for a small percentage of total energy use in these two areas.

\subsubsection{Energy Optimization Based on Building Types at MSOA Level in London}

This section is to compute the overall difference of floor area percentage in terms of gas use intensity at London MSOA level based on the method described in Section 3.4. Table 2 lists the descriptive statistics of the data used in this analysis, including floor area for eight building types and gas use intensity $\left(\mathrm{kWh} / \mathrm{m}^{2}\right)$. Figure 6 shows the results for spatial distributions of overall difference of floor area. The black area is the best performance area in terms of gas use intensity. The white areas in this figure are due to the lack of data and the 951 MSOA areas are used in this analysis.

Table 2. Descriptive statistics in energy optimization analysis [30,34,35].

\begin{tabular}{|c|c|c|c|c|c|c|c|c|c|}
\hline \multirow{2}{*}{ Statistics } & \multicolumn{8}{|c|}{ Floor Area Percentage (\%) } & \multirow{2}{*}{$\begin{array}{c}\text { Gas EUI } \\
\left(\mathrm{kWh} / \mathrm{m}^{2}\right)\end{array}$} \\
\hline & Domestic & Office & Retail & Industry & Culture & Education & Hospital & Others & \\
\hline Mean & 76.47 & 3.90 & 5.81 & 2.69 & 3.75 & 4.39 & 1.84 & 1.14 & 130.70 \\
\hline Median & 81.69 & 0.90 & 4.34 & 0.48 & 2.61 & 3.51 & 0.61 & 0.44 & 130.91 \\
\hline Standard Deviation & 16.33 & 8.46 & 5.26 & 6.00 & 4.65 & 3.65 & 4.28 & 2.07 & 23.28 \\
\hline Kurtosis & 2.63 & 23.92 & 10.54 & 25.44 & 37.98 & 8.38 & 24.93 & 18.20 & 9.15 \\
\hline Skewness & -1.56 & 4.37 & 2.45 & 4.38 & 5.12 & 2.18 & 4.72 & 3.79 & 1.45 \\
\hline Range & 94.34 & 76.90 & 47.50 & 57.66 & 53.49 & 31.60 & 37.43 & 19.23 & 248.31 \\
\hline Minimum & 3.54 & 0.00 & 0.04 & 0.00 & 0.04 & 0.00 & 0.00 & 0.00 & 54.28 \\
\hline Maximum & 97.88 & 76.90 & 47.53 & 57.66 & 53.53 & 31.60 & 37.43 & 19.23 & 302.59 \\
\hline Count & 951 & 951 & 951 & 951 & 951 & 951 & 951 & 951 & 951 \\
\hline
\end{tabular}




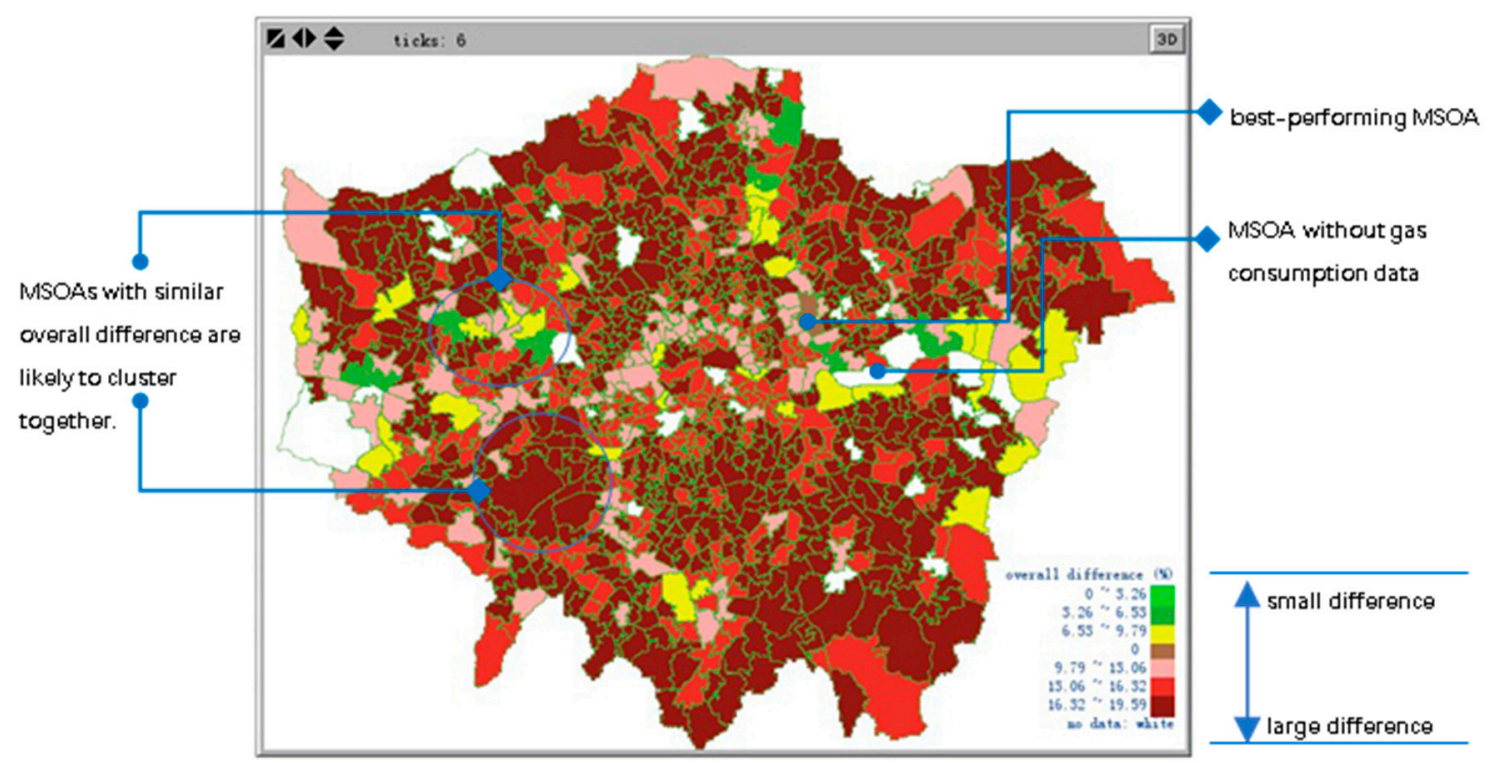

Figure 6. Simulation result of energy efficiency scenario based on urban space form in London MSOA (middle layer super output area) level (black colour, the best performance area; white colour, no data available).

As can be seen from Table 2, the residential building is the dominant type in terms of floor area in London and the variation for the percentage of residential building is also the largest one. Both the kurtosis and skewness values shown in Table 2 can measure the shape of a distribution. The kurtosis is to measure the peak or flat of a distribution and the zero kurtosis means a distribution is close to a normal distribution. In contrast, the skewness is to show the symmetry of a distribution and the zero skewness means a distribution is symmetric. All the kurtosis values in this table are positive, which indicates that all the distributions here are relatively peaked (not flat). Except for residential building, the skewness values for all other types are positive, which means the distributions have the few high values. However, the distribution of floor area percentage for residential buildings has the few low values.

As can be seen from Figure 6, the overall differences of floor area percentage based on gas use intensity are not clustered as large area, but more spread around the London. However, it still presents the characteristics of spatial distribution to some extent. Polygons with less overall difference are apt to cluster together. As mentioned in Section 3.4, the overall difference is computed as the average of all the absolute difference values of floor area for a given MSOA area to best area. Best area is selected based on energy use intensity. The overall difference can reveal the distribution of gas energy consumption. So, Figure 6 is also a demonstration of spatial features in cities, which means that energy consumptions in an area are to some extent influenced by where the area is located in a city. As the basis for spatial analysis and spatial regression, we will add the function in a future version for seeking neighbour polygons and computing neighbour weights matrix.

Figure 7 shows an example that the user can use the apply filters (in a floating window) to select a subset of the building stock as well as the analysis requirements. We can compare the EUI distribution of the selected buildings to the energy optimization area in the district scale. When a specific building type is highlighted, a list of characteristics (building name, type, and total floor area) and its energy use and potential saving data are displayed in a floating window. IUBEA can visualize a suite of performance metrics of buildings by color-coding the view of the energy distribution in district scale. This section shows the efforts that are required to reach the optimum MSOA zone. Figure 7 shows the average metrics ratio coloured according to the grade of effect to the mean metric and optimum in MLSOA within the spatial context of land use (ab) and building size (cd). 


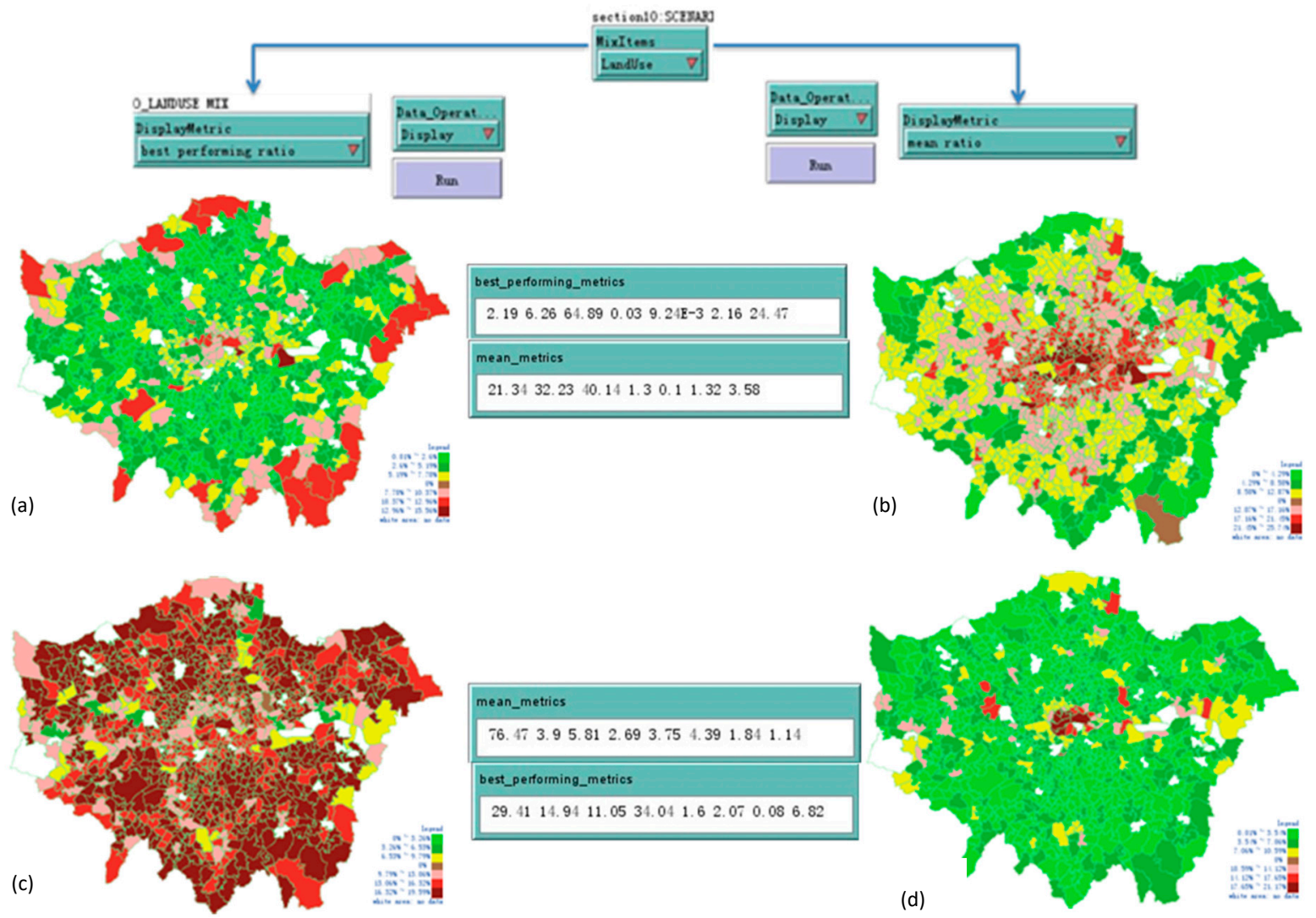

Figure 7. The overall difference to best-performing-ratio MSOA zone and average metrics ratio: (a) Best-performing-ratio of land use; (b) Average metrics ratio of land use; (c) Best-performing-ratio of building size; (d) Average metrics ratio of building size.

\subsubsection{Agent-Based Energy Models in IUBEA}

Figure 8 shows the functions of agent-based energy models in IUBEA. The test case is based on simulation people migrating, according to an accumulation of different energy sources. An initial, simplified module has been created using NetLogo that need to be loosely-coupled to other modules in IUBEA through defined interfaces in NetLogo platform. The ability to examine the effect of socio-economic impacts, such as policy levers or demographic changes will also be included in the model. Weights of each energy source can be set, denoting different policies. From the results each MLSOA has its own distribution of resources and population. Population (agent) will autonomously migrated to find optimal resources in neighbouring MSOA and the polygons (agent) would change distribution of its resources, as well as the variations of EUI. Model will recognize the real time feedback loop to initiate model environment accordingly to the consideration of basic slider individually (which represent the policy in global as well as local).

Statics plots in Figure 8 show how the interaction between energy consumptions, social demographic characteristics, environmental conditions, and human behaviour, which all combine in unique ways to create very different energy saving opportunities for each local authority. In addition, the user can add or adjust settings, sliders, and switches to explore different scenarios or hypotheses. Altering the settings and then running the model to see how it reacts can have a deeper understanding of the energy distribution phenomena in district scale. 


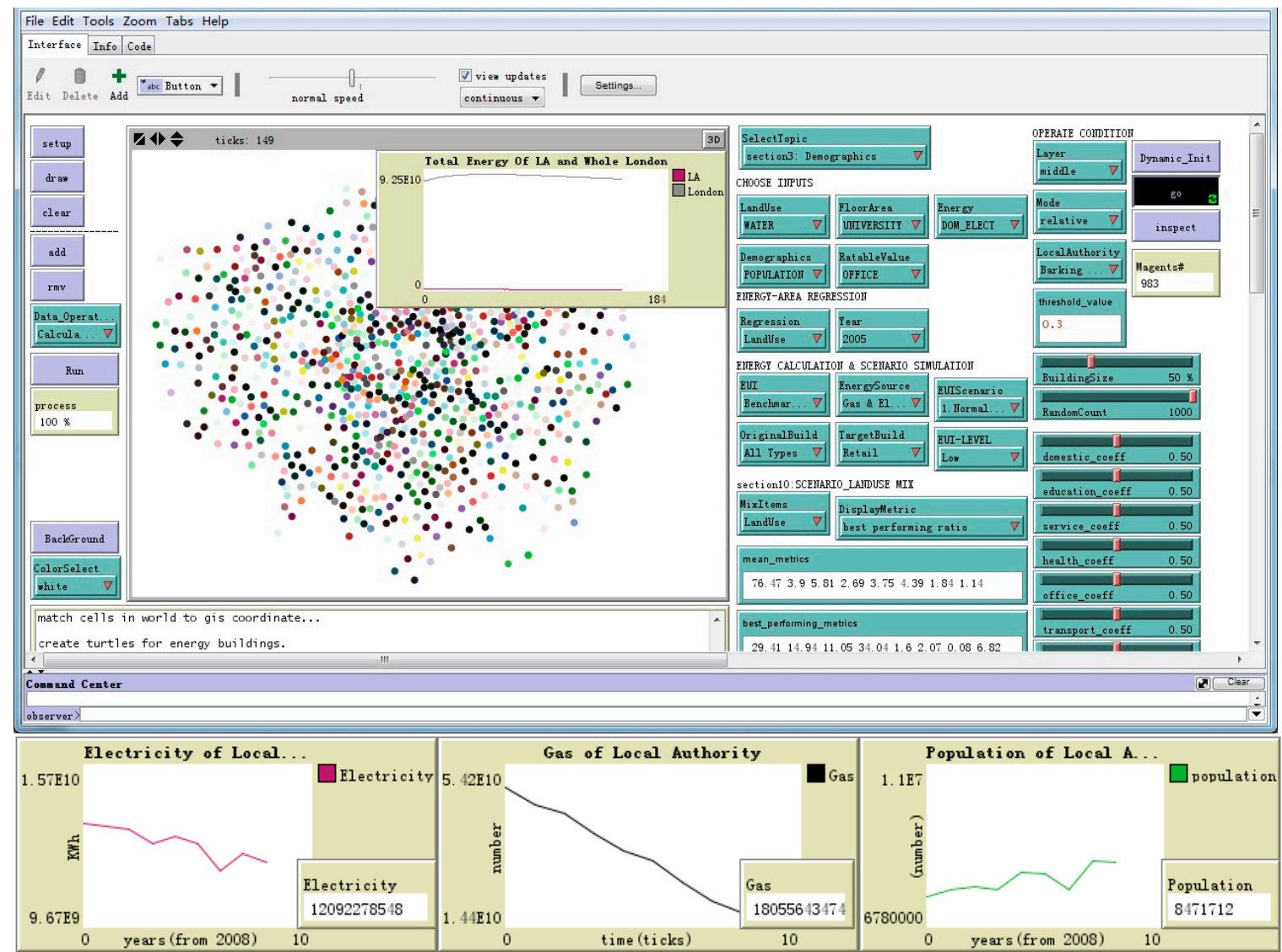

Figure 8. Simulation result of a case ABM for energy efficiency scenario in IUBEA environment.

\section{Discussion}

This paper focuses on model development; we conduct scenario analysis to show the possibility of the ABM model in energy analysis in a district scale. This environment can be used for different locations and analysts can add their own functions for their purposes, such as urban energy planning and design, carbon emissions tracking system, and local laws and code compliance, since this environment is based on public-domain software.

However, there are several limitations in our model. First, in urban planning, there are complex relationships among energy-saving strategy, agent types, reflection behavior, and strategy rules. Further research is required in topic of rules definition to reflect policy diversity. In addition, the operation and implementation of the agent model are based on the assumptions. A gap exists between the assumption and the actual energy, which is a natural uncertainty of the agent-based model. Although random parameters are added to offset the influence of subjective uncertainties, the deviation cannot be completely avoided. Further, thorough the use of more comprehensive data in individual behavior to formulate more realistic behavior, rules of agents will help to improve the practicability of the model.

Moreover, continuous effort is necessary in collecting pertinent time series data to enhance the validity of the developed model. Nevertheless, we believe that our attempt is available as a benchmark approach for future research. As more spatial data related to energy performance in cities is becoming increasingly available, this environment would become more useful for both urban planning and building energy analysis in cities. 


\section{Conclusions and Future Work}

This paper has described a new integrated spatial analysis environment IUBEA to perform a thorough analysis of energy performance in city buildings. This energy analysis environment can be used for multiple functions, including spatial data visualization, data query, regression analysis, scenario analysis, and energy optimization in urban settings. As introduced by the model behavior test, we simulated two scenarios by considering London as a case study with policy influences. The energy scenario analysis, which is used for what-if analysis in this research, can be effective for evaluating effects of new policies. While performing scenario analysis in the IUBEA, results of different scenarios between the local authorities can be easily compared. For illustration, research presents the benefits for electrification in building sector if grid electricity can become gradually less carbon intensive.

As a result, the model validation proved the possibility of the integrated environment in simulation, and the visualization of energy-efficiency analysis is influenced by specialty policies through scenario configuration. While in this work all the simulations were conducted in a virtual space and the simulation results can just reveal the differences between the first and second scenario. Besides, the statistical and parameter mode for energy saving analysis, more scenarios can be considered by city planners, district-level planning practitioners, and energy efficiency policy makers to evaluate design alternatives, retrofit programs, and demand response economics.

Future research will be focused on the following three topics:

1. More diversity of agent-based energy simulation: Due to multiple supply vectors, the model can convert to be or/extend to be a more complex one.

2. Improve in integration of demand response (DR): Future work will be spent improving the integration of the (DR) ABM-module into the IUBEA, expanding the model capability to assess the impact of non-standard dynamic DR policy interventions, such as combined smart metering, incentive-based, and price-based DR programs. So, the model will incorporate the effect of occupant behavior and it will be capable of examining demand side management strategies.

Author Contributions: Conceptualization, Y.S., E.A.S., R.C. and W.T.; Methodology, Y.S., E.A.S., R.C. and W.T.; Software, Y.S.; Validation, Y.S. and W.T. Formal Analysis, Y.S.; Resources and Data Curation, W.T. and R.C.; Writing-Original Draft Preparation, Y.S.; Writing-Review \& Editing, E.A.S., R.C., W.T. and H.L.; Supervision, E.A.S., R.C. and H.L.; Project Administration, E.A.S., R.C.; Funding Acquisition, Y.S. and H.L.

Funding: This research was funded by National Natural Science Foundation of China, Fund No. 51278140; China Postdoctoral Science Foundation, Fund No. 2018M630361; Postdoctoral Science Foundation of Heilongjiang province, Fund No. AUGA4110003717.

Conflicts of Interest: The authors declare no conflicts of interest.

\section{References}

1. Grubler, A.; Fisk, D. Energizing Sustainable Cities: Assessing Urban Energy; Routledge: Abingdon, UK, 2012.

2. Ascione, F.; De Masi, R.F.; de Rossi, F.; Fistola, R.; Sasso, M.; Vanoli, G.P. Analysis and diagnosis of the energy performance of buildings and districts: Methodology, validation and development of Urban Energy Maps. Cities 2013, 35, 270-283. [CrossRef]

3. Robinson, D. Computer Modelling for Sustainable Urban Design; Earthscan: London, UK, 2011.

4. Keirstead, J.; Jennings, M.; Sivakumar, A. A review of urban energy system models: Approaches, challenges and opportunities. Renew. Sustain. Energy Rev. 2012, 16, 3847-3866. [CrossRef]

5. Sailor, D.J. A review of methods for estimating anthropogenic heat and moisture emissions in the urban environment. Int. J. Climatol. 2011, 31, 189-199. [CrossRef]

6. Calderon, C.; James, P.; McCloughlin, A.; Urquizo, J.; Council, N.C. An area-based GIS energy model for cities and neighbourhoods. In Proceedings of the 21st GIS Research UK Conference (GISRUK), Liverpool, UK, 3-5 Apirl 2013.

7. Bourdic, L.; Salat, S. Building energy models and assessment systems at the district and city scales: A review. Build. Res. Inf. 2012, 40, 518-526. [CrossRef] 
8. Sokol, J.; Cerezo, C.; Reinhart, C. Validation of a Bayesian-Based Method for Defining Residential Archetypes in Urban Building Energy Models. Energy Build. 2017, 134, 11-24. [CrossRef]

9. Tian, W.; Yang, S.; Zuo, J.; Li, Z.; Liu, Y. Relationship between built form and energy performance of office buildings in a severe cold Chinese region. In Building Simulation; Tsinghua University Press: Beijing, China, 2017; Volume 10, pp. 11-24.

10. Frayssinet, L.; Merlier, L.; Kuznik, F.; Hubert, J.L.; Milliez, M.; Roux, J.J. Modeling the heating and cooling energy demand of urban buildings at city scale. Renew. Sustain. Energy Rev. 2018, 81, 2318-2327. [CrossRef]

11. Choudhary, R.; Tian, W. Influence of district features on energy consumption in non-domestic buildings. Build. Res. Inf. 2014, 42, 32-46. [CrossRef]

12. Manley, M.; Kim, Y.S. Modeling emergency evacuation of individuals with disabilities (exitus): An agent-based public decision support system. Expert Syst. Appl. 2012, 39, 8300-8311. [CrossRef]

13. Kanaga, E.G.M.; Valarmathi, M.L. Multi-agent based Patient Scheduling Using Particle Swarm Optimization. Procedia Eng. 2012, 30, 386-393. [CrossRef]

14. Lagorse, J.; Paire, D.; Miraoui, A. A multi-agent system for energy management of distributed power sources. Renew. Energy 2010, 35, 174-182. [CrossRef]

15. Jia, M.; Srinivasan, R.S.; Raheem, A.A. From occupancy to occupant behavior: An analytical survey of data acquisition technologies, modeling methodologies and simulation coupling mechanisms for building energy efficiency. Renew. Sustain. Energy Rev. 2017, 68, 525-540. [CrossRef]

16. Kishita, Y.; Yamaguchi, Y.; Umeda, Y.; Shimoda, Y.; Hara, M.; Sakurai, A.; Oka, H.; Tanaka, Y. Describing Long-Term Electricity Demand Scenarios in the Telecommunications Industry: A Case Study of Japan. Sustainability 2016, 8, 52. [CrossRef]

17. Timm, S.N.; Deal, B.M. Effective or ephemeral? The role of energy information dashboards in changing occupant energy behaviors. Energy Res. Soc. Sci. 2016, 19, 11-20. [CrossRef]

18. Hui, B.; Steemers, K. Household archetypes and behavioural patterns in UK domestic energy use. Energy Effic. 2018, 11, 761-771.

19. Zhao, F.; Wang, J.; Koritarov, V.; Augenbroe, G. Agent-based modeling of interaction between commercial building stocks and power grid. In Proceedings of the 2010 IEEE Conference on Innovative Technologies for an Efficient and Reliable Electricity Supply, Waltham, MA, USA, 27-29 September 2010; pp. 225-232.

20. Tian, W.; Heo, Y.; de Wilde, P.; Li, Z.; Yan, D.; Park, C.S.; Feng, X.; Augenbroe, G. A review of uncertainty analysis in building energy assessment. Renew. Sustain. Energy Rev. 2018, 93, 285-301. [CrossRef]

21. Cheng, V.; Steemers, K. Modelling domestic energy consumption at district scale: A tool to support national and local energy policies. Environ. Model. Softw. 2011, 26, 1186-1198. [CrossRef]

22. Fehrer, D.; Krarti, M. Spatial distribution of building energy use in the United States through satellite imagery of the earth at night. Build. Environ. 2018, 142, 252-264. [CrossRef]

23. Tisue, S.; Wilensky, U. NetLogo: A simple environment for modeling complexity. In Proceedings of the International Conference on Complex Systems, Boston, MA, USA, 16-21 May 2004; pp. 16-21.

24. UK Defra \& DECC. 2012 Guidelines to Defra/DECC's GHG Conversion Factors for Company Reporting, Produced by AEA for the Department of Energy and Climate Change (DECC) and the Department for Environment, Food and Rural Affairs (Defra), UK; UK Defra \& DECC: London, UK, 2012.

25. DECC. LLSOA (Lower Layer Super Output Area) Electricity and Gas: 2010; DECC (Department of Energy \& Climate Change): London, UK, 2013.

26. DECC. Total Final Energy Consumption at Regional and Local Authority Level: 2005 to 2010; DECC (Department of Energy \& Climate Change): London, UK, 2009.

27. DECC. MLSOA (Middle Layer Super Output Area) Electricity and Gas: 2010; DECC (Department of Energy \& Climate Change): London, UK. Available online: https:/ / www.gov.uk/government/statistical-data-sets / mlsoa-electricity-and-gas-2010 (accessed on 12 October 2013).

28. EPC (Energy Performance Certificate). DEC (Display Energy Certificate) Database Maintained by Landmark, Department for Communities and Local Government, UK; UK DCLG: London, UK, 2013.

29. UKMap. London Building Database; The GeoInformation Group: Cambridge, UK, 2011.

30. Choudhary, R. Energy analysis of the non-domestic building stock of Greater London. Build. Environ. 2012, 51, 243-254. [CrossRef] 
31. London Datastore. LSOA Atlas, Great https://www.baidu.com/?tn=98012088_4_dg\&ch=12er London Authority, UK. 2013. Available online: http:/ / data.london.gov.uk/datastore/package/lsoa-atlas (accessed on 3 Feburary 2013).

32. VOA. Commercial and Industrial Floorspace and Rateable Value Statistics, UK VOA (Valuation Office Agency). 2013. Available online: http:/ / www.neighbourhood.statistics.gov.uk/ (accessed on 12 October 2013).

33. Carbon Trust. Low Temperature Hot Water Boilers Overview (CTV051); Carbon Trust: London, UK, 2012.

34. Field, A.P. Discovering Statistics Using SPSS; SAGE Publications Ltd.: Thousand Oaks, CA, USA, 2009.

35. Tian, W.; Rysanek, A.; Choudhary, R.; Heo, Y. High Resolution Energy Simulations at City Scale. In Proceedings of the IBPSA Building Simulation Conference (BS2015), Hyderabad, India, 7-9 December 2015.

2018 by the authors. Licensee MDPI, Basel, Switzerland. This article is an open access article distributed under the terms and conditions of the Creative Commons Attribution (CC BY) license (http://creativecommons.org/licenses/by/4.0/). 